\title{
Imunidade inata e específica em plantas
}

\section{Innate and specific immunity in plants}

\author{
Hércules Menezes ${ }^{1}$
}

\section{Resumo}

Plantas e animais são capazes de reconhecer e distinguir entre estruturas moleculares próprias e não-próprias. Estudos recentes nas relações hospedeiro-parasitas têm exposto mecanismos comuns e contrastantes de resistência do hospedeiro tanto em animais como em plantas. Algumas estruturas e estratégias de defesa filogeneticamente antigas têm sido mantidas por desenvolvimento paralelo, enquanto várias outras emergiram mais recentemente durante a filogênese. Embora desprovidas de moléculas de imunoglobulina, células circulantes e processo de fagocitose, as plantas utilizam com sucesso várias defesas físicas e químicas pré-formadas, bem como induzem estratégias de imunidade adaptativa. Esta revisão apresenta a evolução recente nos estudo de aspectos de imunidade comparada, presentes em animais e as plantas.

Palavras-chave: Imunidade em plantas. Imunidade comparada. Resistência sistêmica adquirida.

\begin{abstract}
Plants and animals are able to recognize and distinguish between self and non-self molecular structures. Recent studies concerning host-parasite relations have presented the common and contrasting mechanisms of host resistance in both plants and animals. Some phylogenetically old defense structures and strategies have been maintained by means of parallel development, while several others have emerged more recently during phylogenesis. Although lacking immunoglobulin molecules, circulating cells and phagocytosis process, plants successfully use several pre-established physical and chemical defenses as well as induce adaptive-immune response strategies. This review presents recent developments in the study of comparative immunity aspects that are present in animals and plants.
\end{abstract}

Key words: Immunity in Plants. Compared immunity. Systemic acquired resistance.

1 Possui graduação em Ciências Biológicas pela Universidade de São Paulo (1975), especialização em Jornalismo Científico pelo LABJOR - UNICAMP (2008) especialização em Formação em Psicanálise pelo Centro de Estudos Psicanalíticos (1997), especialização em Immunologie Aprofondie pelo Instituto Pasteur (1980), mestrado em Ciências Biológicas (Biologia Genética) pela Universidade de São Paulo (1981) e doutorado em Ciências Biológicas (Biologia Genética) pela Universidade de São Paulo (1985). E-mail: hermes@rc.unesp.br. 


\section{Introdução}

Durante os últimos 20 anos, uma boa parcela de imunologistas tem mudado o foco de sua atenção, dos mecanismos de imunidade adaptativa, para os mecanismos de imunidade inata (DOHERTY; O'FARRELLY, 2000). Essa mudança no foco da imunologia reflete a importância que os mecanismos e estratégias envolvidos na imunidade inata vêm adquirindo para a melhor compreensão da saúde humana, e mesmo para sua manutenção (SCOTET, et al., 2008).

Muitos componentes da imunidade inata antecedem os mecanismos de imunidade adaptativa, não apenas na ontogenia, como também na filogenia (LEULIER; LEMAITRE, 2008).

O recente aumento no número de estudos acerca dos mecanismos de defesa de outros organismos vivos reflete o interesse dos biologistas em melhor entender o que somos atualmente, baseados no que já fomos no passado evolutivo (MENEZES; JARED, 2002).

A concepção de passividade frente às interferências ambientais, atribuída às plantas, vem sendo revista desde o final do século XIX, quando se iniciaram os estudos de defesa das plantas frente a agentes estranhos. Esta idéia de passividade tem sido drasticamente modificada nas últimas duas décadas, período em que se intensificam os estudos acerca da sinalização que ocorre entre plantas e insetos, entre plantas de mesma espécie e entre plantas de espécies distintas.

O interesse econômico e social em elevar a produção de alimentos agrícolas, oriundo da recente explosão populacional humana que vem ocorrendo na Terra, tem direcionado grandes investimentos para pesquisa e estudos acerca dos mecanismos naturais de defesa dos vegetais contra pestes e patógenos. O foco nos estudos em imunidade em plantas não incide apenas sobre o âmbito econômico, tem interesses no âmbito biológico. A identificação e caracterização de diferentes estratégias de defesa têm estimulado alguns biologistas a procurar traçar um paralelismo entre os sistemas imunes de animais e vegetais (IRITI; FAORO, 2007; MCDOWELL; SIMON, 2008; STASKAWICZ et al., 2001).

Para sobreviver durante cerca de 500 milhões de anos de história evolutiva, esses organismos, sésseis e aparentemente inaptos a responderem a estímulos, desenvolveram e aperfeiçoaram um extraordinário mecanismo de defesa (MENEZES; JARED, 2002).

\section{Imunidade e plantas}

Desde o clássico trabalho de Metchnikoff, em 1887, o processo de fagocitose contra microorganismos invasores tem sido reconhecido como um competente fenômeno geral de defesa de todos os animais. Macrófagos são as células fagocíticas mais bem estudadas dentre as células do sistema imune de vertebrados.

Apesar de não possuírem células circulantes nem apresentarem o processo de fagocitose, as plantas possuem um complexo e eficiente sistema imune (RAIRDAN; MOFFETT, 2007).

A capacidade das plantas em resistir a uma infecção, recuperar-se de doenças e evitar futuras infecções por esse mesmo organismo foi reconhecida e relatada por diversos botânicos nos finais do século XIX e início do XX, concomitante aos estudos de imunologia em animais. Esta capacidade das plantas em responder a infecções subseqüentes por um mesmo microorganismo era denominada de "vacinação de plantas" (CHESTER, 1933), ou "imunização" (KOTHARI; PATEL, 2004) ou, mais recentemente, denominada por Resistência Sistêmica Adquirida - SAR (VLOT; KLESSIG; PARK, 2008).

Uma eficiente captura de luz solar é essencial para a fotossíntese, porém expõe a planta aos danos da radiação UV. O acúmulo de carboidratos provê a planta de uma auto-suficiência metabólica, porém seus tecidos de armazenamento alvos primários para centenas de organismos heterotróficos, desde microorganismos patogênicos até mamíferos 
herbívoros. Mesmo dentro da própria comunidade de plantas existe uma constante competição por recursos, como luz solar, água, minerais ou vetores de polinização e dispersão.

Estima-se (JENSEN, 1986) que, pelo menos, $60 \%$ da biomassa total de uma planta compreendam moléculas que atravessaram a via chiquimato, que leva à produção tanto dos aminoácidos triptofano, fenilalanina e tirosina, precursores de proteínas (metabolismo primário), como compostos fenólicos, alcalóides e glicosídeos cianogênicos (metabolismo secundário). A fenilalanina é tanto um precursor para a síntese de fenilpropanóides tais como lignina, flavonóides e taninos, como um aminoácido essencial para a síntese de proteínas (SHADLE, et. al., 2003).

O crescimento das plantas é diretamente dependente da síntese de proteínas para a manufatura de enzimas fotossintéticas, biosintéticas e regulatórias, bem como proteínas estruturais. Portanto, num certo sentido, a síntese de alcalóides e compostos fenólicos utilizados nos processos de defesa compete diretamente com a síntese de proteínas e, conseqüentemente, com o crescimento (LINDSEY; YEOMAN, 1983; HEGNAUER, 1988).

Embora os compostos resultantes do metabolismo secundário estejam envolvidos em diversos processos fisiológicos, o seu principal papel reside na sua participação nos processos de defesa (WHITTAKER; FEENY, 1971; HARBORNE, 1986). Assim como nos animais, duas principais estratégias de defesa podem ser caracterizadas nos vegetais, as defesas pré-formadas e as defesas induzidas (AGRIOS, 1988). Assim como nos animais, a distinção exata entre essas duas grandes estratégias em alguns momentos é difícil de ser realizada, pois são processos fisiológicos contínuos.

\section{Defesas pré-formadas}

Estruturas celulares e teciduais, bem como compostos químicos, podem atuar como barreiras contra microorganismos invasores.

Para serem consideradas agentes de defesa "pré-formadas" ou "constitutivas" relevantes, essas estruturas ou compostos deverão estar em forma disponibilizada e em concentração suficiente, para apresentar um efeito negativo no crescimento, desenvolvimento e sobrevivência do organismo espoliador. Necessitam, também, ocorrer em células ou tecidos que ainda não entraram em contato com o microorganismo invasor (RAIRDAN; MOFFETT, 2007).

As células vegetais são envolvidas por uma parede celular, cuja estrutura básica é composta de material polimérico, intercalado com celulose. Essas paredes celulares contem variadas quantidades de lignina, um polímero fenólico hidrofóbico. Nas partes aéreas das plantas, formando um sistema de revestimento das folhas, a parede celular está coberta por uma cutícula impermeável constituída de cutina, um poliéster de ácidos graxos hidroxilados. Em dicotiledôneas ocorre ainda uma rede de glicoproteínas transpassando a parede celular (CASSAB; VARNER, 1988).

A parede celular fornece uma barreira estrutural contra microorganismos espoliadores, não apenas em células vivas. Quando as células morrem, suas paredes serão mantidas como constituintes da estrutura vegetal, revestindo e protegendo os troncos, galhos e raízes. Em tecidos internos, constituem as paredes dos vasos condutores de seiva e o aerênquima, tecido de flutuação contendo ar.

A formação da casca nas plantas em muito se assemelha aos sistemas tegumentares de outros seres vivos, seja a pele dos vertebrados com camadas de queratina ou o exoesqueleto dos artrópodes com suas camadas de quitina (CLOUDSLEY-THOMPSON, 1988). 
A destruição da parede celular, seja mecânica ou enzimática, facilita a entrada de microorganismos nos tecidos subjacentes.

Diversos patógenos que podem penetrar no hospedeiro atravessando a epiderme das plantas apresentam a característica de secretar cutinase. In vivo essa enzima é produzida no sítio de penetração e apenas durante um limitado período de tempo, o que torna difícil a sua detecção in vitro (KOLATUKUDY, 1985).

Microorganismos como Mycosphaerella sp., em condições naturais, podem apenas causar doenças quando penetram nos frutos através de escoriações nas suas superfícies. Quando esse microorganismo é alterado geneticamente pela introdução do gene de cutinase em seu genoma, torna-se hábil a atravessar a superfície intacta dos frutos. Nessa última situação, a infecção pode ser bloqueada com a aplicação de anticorpos anti-cutinase na superfície dos frutos (DICKMAN; PODILA; KOLATUKUDY, 1989).

Outro composto constituinte da parede celular que possui função de defesa é a pectina. Muitos microorganismos que conseguem atravessar a parede celular produzem pectinase, entre outras enzimas hidrolíticas. A deleção de genes para pectato ligase na bactéria Erwinia chrysanthemi resultou em uma significante perda da sua virulência (BOCCARA et al., 1988; REID; COLLMER, 1987). A importância dos compostos pécticos na parede celular como barreira pode ser ressaltada pela presença de inibidores de pectinase microbiana na própria parede celular (LAFITTE et al., 1984; LORENZO et al., 1990).

Para as trocas entre os tecidos internos e o ambiente aéreo, as plantas se utilizam de aberturas naturais em sua superfície. Apesar de não serem constatadas evidências diretas, possivelmente $\mathrm{o}$ tamanho, número e localização dos estômatos, hidatódios, lenticelas e pneumatódios possam contribuir para a resistência das plantas a agentes microbianos.

\section{Toxinas}

Todos os compostos sejam de plantas ou animais, que apresentam um efeito negativo sobre o desenvolvimento, crescimento ou sobrevivência de outro organismo, pode ser visto como uma toxina. O mecanismo de ação de algumas toxinas de plantas são bem conhecidos, como das saponinas, que desagregam as membranas celulares (OSBOURN, 1996). O cianeto liberado na decomposição de glicosídeos cianogênicos, armazenados em diversos tecidos vegetais, inibe a respiração celular de diversos espoliadores de plantas (JONES, 1998). Os cardenolídeos são inibidores específicos de $\mathrm{Na} / \mathrm{K}$ ATPase (REPKE; PORTIUS, 1984).

A morfina, com seu conhecido efeito analgésico, é acumulada na papoula Papaver sonniferum, tem um pronunciado efeito no sistema nervoso central de herbívoros, e apresenta também uma atividade de defesa contra patógenos. As peroxidases e moléculas de $\mathrm{H}_{2} \mathrm{O}_{2}$, oriundas da cascata oxidativa desencadeada com o ataque de um patógeno, convertem a morfina acumulada em biamorfina que se liga às moléculas de pectina da parede celular, tornando-a resistente à ação da pectinase liberada pelos agentes patogênicos (MORIMOTO et al., 2001).

O armazenamento de toxinas nas plantas é estrategicamente localizado. Algumas plantas acumulam toxinas em ductos resiníferos e laticíferos ou em tricomas glandulares (DUSSOURD; HOYLE, 2000; HALLAHAN, 2000), de tal forma que estas toxinas sejam liberadas em grandes quantidades imediatamente após a ruptura dessas estruturas, seja em decorrência do ataque de um herbívoro, de movimento na superfície da planta ou do crescimento de um patógeno.

Além da habilidade em sintetizar distintas estruturas químicas, com atividades de defesa individuais, encontram-se misturas complexas como resinas e óleos essenciais, ricos em terpenos. Nessas misturas, à semelhança do que acontece na hemolinfa dos invertebrados e no plasma dos 
vertebrados, as ações de distintos compostos de defesa podem ser sinergisticamente potencializadas por interações moleculares e fisiológicas.

Um típico fenômeno de sinergismo foi demonstrado em ensaios in vitro com o patógeno de batata Clavibacter michiganensis (SEGURA et al., 1999). Em ensaios independentes, o peptídeo snakina-1, expressado principalmente em tubérculos e órgãos reprodutivos de batata, apresentou o mesmo poder de inibição da PTH1, uma defensina (peptídeo de defesa induzido). Quando os ensaios foram realizados com a adição simultânea dos dois peptídeos ao meio de cultura, o poder de inibição da mistura foi acima dos $100 \%$ esperados.

Desconhecem-se quais os mecanismos precisos envolvidos nessas atividades sinergísticas, mas pressupõe-se que a atividade de um desses compostos possa aumentar a absorção do outro, ou mesmo que um deles tenha a habilidade de inibir a destoxicação do outro composto (ZANGERL; STANLEY; BERENBAUM, 2008).

Dois grandes problemas emergem com a produção de toxinas pelas plantas. O primeiro é a necessidade de conviver com estes compostos tóxicos. Eles devem ser sintetizados e estocados e, portanto, apresentam um perigo para as próprias plantas produtoras.

A segunda questão é a do investimento energético para a defesa. Os limitados recursos nutricionais disponíveis para esses organismos sésseis deverão ser distribuídos entre o metabolismo de crescimento e o metabolismo de defesa, ou em outras palavras, as plantas necessitam optar entre o seu crescimento e a sua defesa.

No primeiro problema, uma estratégia para evitar a toxicidade de seu arsenal químico de defesa é a de armazenar as toxinas em forma de precursores inativos. Em plantas da ordem Capparales, as moléculas de glucosinolase, um ciano-glicosídeo, estão compartimentalizadas separadamente, mas justapostas a células contendo estoques de moléculas dethioglucosidase mirosinase, a enzima que hidrolisa o glicosídeo liberando isothiocianato tóxico (RASK et al., 2000; WITTSTOCK; HALKIER, 2000). A ruptura da parede celular pelo espoliador promove a combinação dos dois compartimentos, ativando assim a toxina.

Estudos em Arabidopsis thaliana (KOROLEVAet al., 2000; ANDRÉASSON et al., 2001) indicam que as "S-cells", células ricas em compostos sulfúricos, situadas na haste floral, entre o floema e a epiderme, contêm altas concentrações de glucosinolatos. Já as moléculas de mirosinases estão localizadas nas células do parênquima, adjacentes ao floema. Os danos em torno do floema colocam em contato as moléculas de mirosinases e glucosinolatos e esses últimos são irreversivelmente hidrolisados em agliconas instáveis. Essas agliconas são, por sua vez, rearranjadas em diversos compostos biologicamente ativos, principalmente isothiocianatos e nitrilos.

Após a ativação e liberação das toxinas, a necessidade subseqüente será a remoção ou inativação dos compostos ativos residuais. No caso acima, catálises por meio de metiltransferases e nitilases, respectivamente, seriam as responsáveis pela destoxicação da planta, subseqüente ao ataque do espoliador (ATTIEH; SPARACE; SAINI, 2000; VON RAD et al., 2001).

Outra situação pertinente à liberação de toxinas refere-se às plantas circunvizinhas daquela atacada. As toxinas benzoxazinoides, encontradas principalmente em gramíneas, são outra classe de glicosídeos que são ativados após uma danificação tecidual (SICKER et al., 2000). Um D-glicosídio inativo pode ser hidrolisado na fitotoxina aglicana DIBOA (2,4-dihidroxi-1,4-benzoxazin-3-1) e na sua forma metilada DIMBOA (VOLOSHCHUK et al., 2007). No milho (VON RAD et al., 2001), a catálise da DIBOA e da DIMBOA é efetuada por duas enzimas glucosiltransferases, codificadas respectivamente pelos genes $B X 8$ e $B X 9$, os quais são ativados após os níveis de DIBOA e DINBOA alcançarem um nível tóxico ao hospedeiro.

Espécies dicotiledôneas conseguem degradar 
as moléculas de benzoxazinoides, liberadas pelas gramíneas ao seu redor, por meio de reações de hidroxilização e N-glicosilação (VOLOSHCHUK et al., 2007).

Mesmo frente a estas toxinas produzidas pelas plantas, diversos espoliadores especializados desenvolveram estratégias bioquímicas e comportamentais que lhes possibilita evitar o efeito dessas toxinas.

Estudos mais acurados foram realizados com larvas de lepidópteros dos gêneros Papileo e Helicovespa(COHEN;SCHULER;BERENBAUM, 1992; MAet al., 1994). A metabolização de moléculas tóxicas de furocoumarina que ocorrem em plantas das famílias Apiaceae e Rutaceae é realizada por moléculas de citocromo P450s, encontradas nesses insetos. Quanto mais especializados forem esses herbívoros, maior a expressão de citocromo P450s nesses insetos.

Alguns fungos patogênicos são capazes de metabolizar a saponina de seus hospedeiros (OSBOURN, 1996). A planta Avena sativa quando atacada pelo fungo Stagonospora avenae, responde com a produção de um composto antifúngico derivado da saponina, o 26-desglucoavenacosídeo. Em contrapartida, o fungo responde com a produção de três enzimas hidrolíticas, uma $\alpha$-ramnosidase e duas $\beta$-glucosidases, resultando numa acentuada redução da atividade antifúngica da planta (MORRISSEY; WUBBEN; OSBOURN, 2000).

\section{Defesas induzidas}

Compostos com função defensiva sempre acarretam custos às plantas, pois deslocam e consomem recursos para sua biossíntese. Nos casos de defesa constitutiva, esses custos são pagos mesmo sem o ataque do patógeno.

Por serem em geral tóxicos para as próprias plantas produtoras, elas necessitam ao mesmo tempo, investir em mecanismos de controle dessa toxicidade. Uma estratégia para a redução desses custos de defesa é sintetizar os compostos de defesa somente após o ataque inicial do patógeno ou herbívoro. Certamente essa estratégia pode ser arriscada, pois o ataque pode ser rápido ou severo o suficiente para que não haja tempo de resposta por parte da planta.

Comparada à resistência constitutiva, a defesa induzida em plantas implica um baixo custo de defesa, mas, presumivelmente, também um alto custo de herbivoria, desde que um dano inicial é requerido para a indução.

Defesas induzidas podem ser definidas de maneira generalística, como sendo alterações fenotípicas elicitadas diretamente pela ação de agentes bióticos. Essas alterações geralmente são capazes de reduzir o efeito de um subseqüente ataque por parte deste agente específico, assemelhando-se à memória do sistema imune dos vertebrados.

As defesas induzidas se iniciam pelo reconhecimento do agente agressor e a ativação de genes específicos, cujos produtos irão interferir em vias metabólicas distintas, mas que, ao final, resultarão na formação de barreiras bioquímicas e barreiras físicas ou estruturais, que reduzirão a eficiência do agente espoliador. Essa indução pode ocorrer no local da infecção, sistemicamente ou mesmo em ambas as situações.

\section{Reforço da parede celular}

Além de polissacarídeos e proteínas, as paredes celulares contêm lignina, um complexo polímero fenólico hidrofóbico, resistente à degradação microbiana. O espessamento da parede celular, por meio da incrustação de lignina, é induzido localmente por vários fungos patogênicos (KIRT, 1971).

A composição da lignina induzida em resposta a um agente agressor é marcadamente diferente da encontrada na planta não infectada. Em raízes do rabanete japonês, a forma de lignina encontrada em suas paredes celulares é a da guaiacil- 
siringil lignina. Após a infecção com o fungo Peronospora parasitica, ocorre uma substituição desta forma nativa por lignina enriquecida com p-hidroxifenilpropano e guaiacilpropano (ASADA; MATSUMOTO, 1971). Alterações na composição da lignina depositada na parede celular são também observadas após infecções experimentais em batata (HAMMERSCHMIDT, 1999), trigo (RIDE, 1975) e melão (TOUZÉ; ROSSIGNOL, 1977).

Utilizando-se dos precursores radioativos de lignina, fenilalanina e ácido cinâmico (DEAN; KUC, 1987), foram possíveis observar uma rápida assimilação destes compostos após infecções experimentais em abóbora. Nesses experimentos também se verificou que a aceleração na incorporação dos precursores de lignina se fazia tanto no local da infecção como sistemicamente.

Paralelamente à deposição induzida de lignina, ocorre um aumento na presença de glicoproteínas ricas em hidroxiprolina (HPRGs) (CORBIN; SAUER; LAMB, 1987; MAZAU; ESQUERRÉTUGAYÉ, 1986). Os genes que codificam HPRGs pertencem a uma família gênica cuja regulação depende da interação com o patógeno. Embora ainda de função desconhecida, supõe-se que os locais ricos em HPRGs correspondam a sítios sinalizadores para a lignificação (CORBIN; SAUER; LAMB, 1987).

\section{Oclusão de vasos}

A oclusão de vasos, tanto do xilema como do floema, podem ocorrer em resposta ao estabelecimento de microorganismos nestes locais. Estas oclusões podem ser acarretadas pelo acúmulo de géis e gomas ou por formação de tiloses. Estas últimas são protusões das paredes celulares do parênquima vascular, que penetram no lúmem dos elementos de vaso.

Em carvalhos e elmos (JACOBI; MCDONALD, 1980), a rápida formação de tiloses é um importante fator de resistência do hospedeiro, que circunscreve os patógenos e seus esporos. A oclusão vascular através do acúmulo localizado de goma, também limita a dispersão da Xillela fastidiosa, causadora da Doença de Pierse em videiras e na Doença do Amarelinho na laranja (MOLLENHAUER; HOPKINS, 1976).

Essa obstrução no sistema de transporte da planta pode acarretar efeitos deletérios ao hospedeiro, diminuindo a produção de frutos ou mesmo provocando a morte. Situações semelhantes são bem conhecidas em humanos, onde a resposta do sistema imune acarreta danos colaterais ao hospedeiro, como no caso da Elefantíase, Cisticercose e Schistosomose.

\section{Resposta hipersensitiva}

Uma importante estratégia do sistema imune de plantas é denominada de resposta hipersensitiva ou $\mathrm{HR}$, que consiste na indução de morte celular no local da infecção (GREENBERG, 1996). Diversos genes envolvidos na cascata de indução de morte celular foram identificados em plantas e apresentam homologia com genes humanos, também envolvidos neste fenômeno de morte celular (ARAVIND; DIXIT; KOONIN, 1999).

A conseqüência da morte celular localizada é a restrição de nutrientes e água ao patógeno, circunscrevendo desta maneira o espectro de ação do microorganismo. Essa é uma resposta de defesa principalmente contra vírus, embora também ocorra contra bactérias e fungos.

Diversos estudos indicam que a danificação da membrana citoplasmática do hospedeiro seja o primeiro evento que dispara a reação de HR. Em culturas celulares de tabaco, quando em presença de Pseudomonas syringae, foi evidenciado um aumento no fluxo $\mathrm{H}+/ \mathrm{K}+$ pelas membranas das células (ATKINSON; HUANG; KNOPP, 1985). Em experimentos com feijão, utilizandose de uma linhagem Tn5 de $P$. syringae, que não possuia a característica de induzir $H R$, não foi também observada alterações no influxo $\mathrm{H}+/ \mathrm{K}+$ 
na membrana celular dessas células (ATKINSON; BAKER, 1989).

\section{Galhas}

Quando alguns insetos, nemátodas ou bactérias se alojam em uma planta hospedeira pode ocorrer a formação de galhas. Estas podem ser definidas como nichos onde populações de parasitos sobrevivem dentro de condições metabólicas especiais.

Galhas induzidas por seis diferentes espécies de vespas do gênero Pantania em seis diferentes espécies de carvalho induziram a produção de 36 compostos fenólicos distintos, que não são detectados em folhas de carvalho não infestadas (NYMAN; JULKUNENTITTO, 2000). Esses compostos químicos de defesa induzidas se acumulam no tecido da galha, mas nem sempre impedem que esses insetos completem parte de seus ciclos de vida na planta, eclodindo no estado adulto.

Algumas bactérias, dentre elas a micobactéria Rhodococcus fascians, apresentam a propriedade de formar galhas em folhas. Essa capacidade tumorigênica de $R$. fascians em induzir a formação de galha está relacionada com alterações hormonais locais no hospedeiro, como queda nos níveis de auxina e aumento nos níveis de AIA (GOETHALS et al., 2001). Embora histologicamente diferente de outras galhas causadas por outras bactérias, todas elas tem em comum a característica de inibir a produção de compostos fenólicos de defesa pelo hospedeiro (GOETHALS et al., 2001).

Nematóides de diversos gêneros podem espoliar externa ou internamente raízes de diversas plantas. Quando nemátodas endoparasitas interagem com o hospedeiro, eles induzem a formação de um "sitio de alimentação do nemátoda", ou NFS (FAVERY et al., 1998). Nessas estruturas, os parasitos são capazes de induzir a desdiferenciação de células da raiz e alimentar-se das mesmas. As secreções glandulares de vermes Meloidogyne spp. promovem a formação de células gigantes. Já indivíduos das espécies Heterodera spp. e Globodera spp. induzem nesses NFSs a formação de sincícios, oriundos de até 200 células (HUSSEY, 1989). Em adição ao núcleo alimentar, esses nemátodas também induzem a divisão de células corticais em torno dos NFSs, formando um típico "nó de raiz".

Análises comparativas na expressão diferencial de genes em plantas resistentes e plantas infectadas tornaram possível identificar diversos genes de resistência a nemátodas (NIEBEL et al., 1996; LAMBERT et al., 1999). Em algumas plantas como tomate, esses mesmos genes podem também ser ativados pela inoculação de certas bactérias ou micorrizas.

\section{Fitoalexinas}

Em 1911 o botânico francês Noel Bernard observou que plantas podiam produzir substâncias antifúngicas específicas, formadas após a infecção por fungos. Ele verificou que o tubérculo de duas espécies de orquídeas (Orchis morio e Loroglossum hircinum) desenvolvia resistência a futuras inoculações, após terem sido previamente infectadas pelo fungo Rhizoctomia repens. Ao aplicar sobre o meio ágar os fragmentos de tubérculos infectados e, posteriormente, inocular o fungo sobre o meio, Bernard observou que o tecido vegetal infectado produzia um inibidor de crescimento do fungo e que este se difundia no meio. Entretanto, os compostos envolvidos nesta resposta imune só foram identificados algumas décadas mais tarde (VANETTEN; TEMPORINI; WASMANN, 2001).

Em 1941, dois botânicos alemães Müller e Börger, observaram o mesmo fenômeno em tubérculos de batata infectados por Phytophthora infestans e denominaram estas substâncias induzidas de "fitoalexinas" $(\phi \cup \tau o v=$ planta; $\alpha \lambda \varepsilon \xi \varepsilon \iota v=$ em defesa) e as definiram como "compostos químicos produzidos como resultado da invasão de células vivas por parasitos". Essa definição tem sido frequentemente modificada e hoje se aceita que sejam compostos de baixo peso molecular que 
atuem como antibióticos restritos ao local de ataque do patógeno e induzidos tanto por fatores bióticos como em resposta a fatores químicos e ambientais (HAMMERSCHMIDT, 1999). Cerca de 300 diferentes metabólicos secundários são denominadas de fitoalexinas, não se aplicando este termo a peptídeos antifungos ou outras proteínas produzidas pelas plantas.

\section{Defensinas}

Uma família de moléculas que, mais recentemente vêm chamando a atenção dos pesquisadores da área, compreende as defensinas. Esses pequenos peptídeos catiônicos $(\sim 5 \mathrm{kDa})$, ricos em cisteina, podem inibir diretamente o crescimento de microorganismos, bem como indiretamente, estimular o sistema imune do hospedeiro. O fato de estarem presente em plantas, insetos e vertebrados (STEGEMANN et al., 2009), faz pressupor que seja uma das estratégias de defesa mais antigas dentre os organismos multicelulares.

Esta ampla distribuição na natureza, associada às suas múltiplas propriedades funcionais, fazem destas moléculas o foco de investigações bioquímicas, visando a finalidades terapêuticas (SANG; BLECHA, 2008).

\section{Resposta integrada de defesa da planta contra a infecção do patógeno}

Nas interações incompatíveis planta-patógeno, os danos causados pelo patógeno são restringidos devido aos processos de imunidade da planta. Esses processos implicam a coordenação de sinais moleculares que ativam regiões do genoma da planta, para a transcrição final de um grupo de proteínas novas denominadas coletivamente de "pathogenesis-related proteins", ou PRs.

Essas PRs, além de serem produzidas no local da infecção, são também induzidas sistemicamente, tomando parte ativa na eliminação do agente patogênico e no desenvolvimento da Resistência
Sistêmica Adquirida, ou SAR, contra futuros ataques desse patógeno.

A SAR esta associada com a indução no aumento de níveis de proteínas, bem como de outros compostos como saponinas, melaninas, taninos, alcalóides, $\mathrm{NO}$ (óxido nítrico), flavonóides, $\mathrm{H}_{2} \mathrm{O}_{2}$, etc. (BELL; CHARLWOOD, 1980).

O amplo espectro dos compostos da SAR promove uma imunidade integrada e de longa memória contra o patógeno indutor, no local da infecção bem como em tecidos não infectados. Infecções experimentais algumas vezes resultam nesta resistência patogenoespecífica (THOMPSON; BURDON, 1992), mas a proteção induzida pode ser também inespecífica (ELLIS; DODDS; PRYOR, 2000).

A base genética da imunidade em plantas foi inicialmente proposta na década de 1940, mais recentemente reformulada (FLOR, 1971) e conhecido como modelo "Gene-for-Gene". As interações planta-patógeno, particularmente aquela envolvendo parasitas biotróficos, são governadas por interações específicas entre produtos gênicos do lócus $a v r$ (avirulência) encontrados no patógeno e por produtos do lócus $R$ (resistência à doença), encontrados nas plantas. Quando um alelo do lócus $R$ está presente na planta e o correspondente $a v r$ no patógeno, especificamente esta planta resistirá ao patógeno. Entretanto, a não expressão do $R$, seja por ausência ou inativação do alelo, acarretará a doença.

Este modelo pressupõe que, para ocorrer à interação genética planta-patógeno os produtos $R$ devam reconhecer o sinal avr e disparar uma cadeia de eventos que culminem com a ativação da resposta imune da planta e o conseqüente controle da espoliação do patógeno.

Os genes $R$ estão envolvidos na resistência a patógenos, sejam vírus, bactérias, fungos, nemátodas ou insetos. Embora o espectro dos patógenos seja extremamente amplo, o número de genes $R$ é bastante reduzido. Mais de 30 genes de resistência 
a doenças foram isolados de diversas espécies de plantas (HULBERT et al., 2001).

A maioria desses genes é polimórfica e expressam proteínas $\mathrm{PR}$, cuja estrutura básica apresenta uma região rica em seqüências repetitivas de leucina denominadas LRRs e outra região denominada NBS, por ser uma seqüência que se liga a nucleotídeos. Em Arabidopsis cerca de 1\% do seu genoma compreende de genes $R$ (YOUNG, 2000) e o número de seqüências codificadoras de NBSLRR varia de 200 a 300 (MEYERS et al., 1999). Em plantas de arroz, este valor estimado está acima de 1500 (MORRISSEY; WUBBEN; OSBOURN, 2000).

O domínio LRR é encontrado em diversas proteínas, tanto animais como vegetais, e é um conhecido sítio de interação proteína-proteína e proteína-carboidrato (JONES; JONES, 1997; KAJAVA, 1998). Já o domínio NB é conservado. A sua função é conhecida em outras proteínas, onde também ocorre, e é um domínio que pode se ligar a moléculas de ATP ou GTP (SARASTE; SIBBALD; WITTINGHOFER, 1990).

Diversas revisões têm sido publicadas ultimamente sobre a estrutura e função desses genes (DANGL et al., 1992; ELLIS; DODDS; PRYOR, 2000; ELLIS; JONES, 1998; HULBERT et al., 2001). Do ponto de vista da biologia, um aspecto interessante desses genes refere-se ao processo evolutivo.

Muitas destas seqüências gênicas são encontradas em invertebrados e vertebrados, codificando também proteínas envolvidas nas respostas imunes destes organismos, como no caso do Toll em drosófilas e mamíferos e os receptores de Interleucina-1 em mamíferos (HULBERT et al., 2001). Certamente essas homologias refletem um alto valor adaptativo embutido nesses sinalizadores.

Alguns trabalhos recentes sugerem que $o$ polimorfismo dos genes $R$ deva ter se originado através de duplicações gênicas, seguidas de mutações pontuais e deleções intragênicas, que teriam levado à produção de seqüências de DNA divergentes (MALECK et al., 2002). Os blocos ricos em leucina teriam se originado através de duplicações intragênicas. Recombinações genéticas entre alelos foram encontradas (ELLIS; DODDS; PRYOR, 2000; HULBERT et al., 2001) e sugeridas como mecanismo capazes de gerar novos alelos.

Certamente, as pressões seletivas dos patógenos, durante o decorrer da evolução das plantas, devam ter direcionado para a diversidade dos genes $R$, ao mesmo tempo em que para a manutenção da especificidade observada hoje em dia.

Apesar das homologias genéticas observadas entre animais e plantas, o que chama a atenção é o paralelismo observado entre plantas e animais com respeito ao sistema imune adaptativo de ambos, o que possibilita algumas formulações:

$1^{\circ}$ Tanto em camundongos (LEDER et al., 1974) quanto em plantas, cerca de $1 \%$ do genoma está comprometido com a elaboração de proteínas que protegem de forma específica seus hospedeiros contra patógenos: imunoglobulinas nos vertebrados, e PRs nas plantas.

$2^{\circ}$ Para controlar a enorme diversidade de patógenos, tanto os vertebrados como as plantas dispõem de um sistema imune adaptativo composto por proteínas com um extremo grau de diversidade estrutural, mas restritas a poucas classes. Cinco classes de imunoglobulinas para camundongos e cerca de catorze classes de PRs para as plantas.

$3^{\circ}$ Os recentes estudos de evolução molecular, tanto em plantas quanto em vertebrados, têm apontado para o fato de que os eventos evolutivos que ocorreram para a geração de diversidade em PRs e imunoglobulinas foram os mesmos:

I) duplicações de uma forma pré-existente;

II) ocorrência de pequenas variações nas formas duplicadas, decorrentes de eventos diferenciais;

III) incremento desta diversidade através de recombinações. 
IV) a seleção dessa diversidade através de confrontamentos com o meio ambiente.

\section{Sinalizadores da resposta imune}

Os sinais precisos que levam ao estabelecimento da SAR não estão ainda bem definidos, mas estudos com plantas transgênicas indicam ter o ácido salicílico um papel central nos processos de sinalização (DELANEY et al., 1994). Algumas plantas após sofrerem alguma injúria, liberam metilsalicilato, um derivado volátil do ácido salicílico que pode ser percebido por plantas vizinhas da mesma espécie, induzindo-as a ativar seus mecanismos de defesa (SHULAEV; SILVERMAN; RASKIN, 1997; PARK et al., 2007).

O ácido jasmônico (REYMOND et al., 2000) e o etileno (SIVASANKAR; SHELDRICK; ROTHSTEIN, 2000) são também importantes moléculas sinalizadoras.

Em uma abordagem inicial, para se entender os processos associados à resistência específica das plantas, muitos estudos foram direcionados na procura de proteínas que pudessem atuar como imunoglobulinas. Até o momento não foram encontradas moléculas da superfamília de imunoglobulinas, mas, pelo menos 10 diferentes famílias de genes $R$, produzindo PRs, inclusive as seqüências NBS-LRR foram identificadas nestes últimos vinte anos (KITAJIMA; SATO, 1999). Estas famílias gênicas são também designadas como "genes SAR" (WARD et al., 1991).

Mesmo sem células circulantes, o sistema vascular das plantas pode, eficientemente, ter vários fatores sinalizadores, entre eles peptídeos e RNA através da planta (KUHN et al., 1997). O sistema vascular das plantas não transporta apenas RNA viral, mas, também RNA mensageiros e RNA silenciadores (CITOVSKY; ZAMBRYSKI, 2000).

As células de plantas são algumas vezes ligadas por pontes citoplasmáticas que passam através de poros na membrana citoplasmática entre células adjacentes Estas junções são denominadas plasmodesmatas e possibilitam o transporte seletivo de moléculas sinalizadoras endógenas específicas, sem saírem do meio citoplasmático (DING, 1997).

Para imunologistas de animais, um intrigante aspecto do sistema imune de plantas é a ausência de processos de fagocitose. Vesículas pinocíticas (BLACKBOURN; JACKSON, 1996) e contendo clatrina (ROBINSON, 1996) tem sido descritas apenas em tubos polínicos e membranas celulares de células em cultura de tecido. Únicas situações em que essas células não estão circundadas pela parede celular (THIEL; KREFT; ZOREC, 1998). Estas ocorrências endocíticas estão aparentemente associadas com os processos de reciclagem da membrana (BATTEY et al., 1999; MARTY, 1999). Por serem autotróficas, é de se esperar que as ocorrências de vacúolos digestivos no citoplasma, estejam relacionadas apenas com autofagia, sendo a digestão limitada à reciclagem de materiais "próprios". Em contraste, os animais digerem materiais "próprios" e "não-próprios".

\section{Termorregulação}

Alterações fisiológicas decorrentes da interação planta-patógeno afetam os estômatos no local da infecção. $\mathrm{O}$ ácido acetil-salicílico, componente sinalizador central da resistência a doenças, diminui a abertura do estômato em diversas plantas. Toxinas produzidas pela bactéria patogênica Pseudomonas syringae também ocasionam o fechamento dos estômatos (DIGIORGIO et al., 1996). Outros compostos não identificados produzidos durante a HR também promovem a oclusão dos estômatos (MCDONALD; CAHIL, 1999).

O monitoramento termográfico (ENYEDI et al., 1992) e o monitoramento por análise infravermelha de gás, ou IRGA (CHAERLE et al., 2004) em folhas de tabaco infectadas com TMV, mostraram um incremento de $0,6^{\circ} \mathrm{C}$ no sítio de infecção, acompanhado de uma queda de $0,9^{\circ}$, após a morte 
celular no local. Esse aquecimento localizado é decorrente da restrição na transpiração, ocasionada pelo fechamento do estômato.

Plantas infectadas com TMV apresentam uma queda no fluxo de água através do xilema e o fechamento dos estômatos seria uma compensação para se evitar a perda excessiva de água pelas superfícies da planta, protegendo-a de uma desidratação (MEYER; GENTY, 1999).

Entretanto, analisando-se estes trabalhos de outro ponto de vista, poderemos interpretar que a queda do fluxo de água no xilema seja decorrente do fechamento dos estômatos e não a causa deste último fenômeno. Outro ponto é que o fechamento dos estômatos ocorre no local da infecção. Estômatos de regiões não infectadas da planta permanecem abertos.

Na década de 1950, uma série de estudos in vitro de viroses animais indicou que esses organismo são extremamente sensíveis a variações de temperatura. Variações de $0,5^{\circ} \mathrm{C}$ são suficientes para inativar diversos desses microorganismos, o que se fez pensar na associação de uma função virilicida aos aumentos da temperatura corpórea após uma infecção viral.

Certamente a queda de $0,9^{\circ} \mathrm{C}$ verificada em regiões de ocorrência de $\mathrm{HR}$, decorra da morte celular e cessamento do metabolismo no local, mas o aumento de $0,5^{\circ} \mathrm{C}$ logo após a infecção viral poderia representar um dos primórdios de uma reação inflamatória.

\section{Conclusões}

Plantas e animais estão equipados com moléculas, células, tecidos e órgãos que os torna capacitados a distinguir o que é "próprio" do que é "não próprio" e, dessa maneira, mediar suas relações com o indivíduo e o meio ambiente. Algumas destas estratégias e estruturas utilizadas por esses seres vivos são filogeneticamente antigas, refletindo os seus altos valores adaptativos.
Durante suas histórias evolutivas, as diferentes rotas percorridas por estes organismos distintos resultaram em estruturas e estratégicas filogeneticamente mais recentes e distintas.

Apesar dessa mescla de similaridades e dissimilaridades, todas essas estratégias e estruturas possuem um final comum: Manter a integridade dos indivíduos frente a parasitos.

\section{Referências}

AGRIOS, G. N. Plant Pathology. London: Academic Press, 1988. p.922.

ANDRÉASSON, E.; JØRGENSEN, L. B.; HÖGLUND, A. S.; RASK, L.; MEIJER, J. Different myrosinase and idioblast distribution in Arabidopsis and Brassica napus. Plant Physiology, Rockville, v. 127, n. 4, p. 1750-1763, 2001.

ARAVIND, L.; DIXIT, V. M.; KOONIN, E. V. The domains of death: evolution of the apoptosis machinery. Trends in Biochemical Sciences, London, v. 24, n. 2, p. 47-53, 1999.

ASADA, Y.; MATSUMOTO, I. Lignin Formation In Fungus Infected Plants .4. Microspectrophotometric Observations On Cell Walls Of Japanese Radish (Raphanus sativus) Root Infected By PeronosporaParasitica. Physiological Plant Pathology, London, v. 1, n. 4, p. 377-381, 1971.

ATKINSON, M. M.; BAKER, C. J. Role of the Plasmalemma H-ATPase in Pseudomonas syringaeInduced K/H Exchange in Suspension-Cultured Tobacco Cells. Plant Physiology, Rockville, v. 91, n. 1, p. 298303, 1989.

ATKINSON, M. M.; HUANG, J. S.; KNOPP, J. A. The hypersensitive reaction of tobacco to Pseudomonas syringae pv. pisi: activation of a plasmalemma K/H exchange mechanism. Plant Physiology, Rockville, v. 79, n. 3, p. 843-847, 1985.

ATTIEH, J.; SPARACE, S. A.; SAINI, H. S. Purification and properties of multiple isoforms of a novel thiol methyltransferase involved in the production of volatile sulfur compounds from Brassica oleracea. Archives of Biochemistry and Biophysics, San Diego, v. 380, n. 2, p. 257-266, 2000.

BATTEY, N. H.; JAMES, N. C.; GREENLAND, A. J.; BROWNLEE, C. Exocytosis and endocytosis. Plant Cell, Rockville, v. 11, n. 4, p. 643-659, 1999. 
BELL, E. A.; CHARLWOOD, B. V. Secondary plant products. New York: Springer-Verlag, 1980. p. 674.

BLACKBOURN, H. D.; JACKSON, A. P. Plant clathrin heavy chain:sequence analysis and restricted localisation in growing pollen tubes. Journal of Cell Science, Cambridge, v. 109, n. 4, p. 777-786, 1996.

BOCCARA, M.; DIOLEZ, A.; ROUVE, M.; KOUTOUJANSKY, A. The role of individual pectate lyases of Erwinia chrysanthemi strain 3937 in pathogenicity on saintpaulia plants. Physiological and Molecular Plant Pathology, London, v. 33, n. 1, p. 95104, 1988.

CASSAB, G. I.; VARNER J. E. Cell wall proteins. Annual Review of Plant Physiology and Plant Molecular Biology, Palo Alto, v. 39, p. 321-353, 1988.

CHAERLE, L.; HAGENBEEK, D.; BRUYNE, E.; VALCKE, R.; VAN DER STRAETEN, D. Thermal and chlorophyll-fluorescence imaging distinguish plantpathogen interactions at an early stage. Plant and Cell Physiology, Oxford, v. 45, n. 7, p. 887-896, 2004.

CHESTER, K. S.The problem of acquired physiological immunity in plants. Quarterly Review of Biology, Chicago, v. 8, n. 3, p. 275-324, 1933.

CITOVSKY, V.; ZAMBRYSKI, P. Systemic transport of RNA in plants. Trends in Plant Science, London, v. 5, n. 2, p. 52-54, 2000.

CLOUDSLEY-THOMPSON, J. L. Evolution and Adaptation of Terrestrial Arthropods. New York: Springer-Verlag, 1988. p. 141.

COHEN, M. B.; SCHULER, M. A.; BERENBAUM, M. R. A host-inducible cytochrome P-450 from a hostspecific caterpillar: molecular cloning and evolution. Proceedings of the National Academy of Sciences of the United States of America, Washington, v. 89, n. 22, p. 10920-10924, 1992.

CORBIN, D. R.; SAUER, N.; LAMB, C. J. Differential regulation of a hydroxyproline-rich glycoprotein gene family in wounded and in infected plants. Molecular and Cellular Biology, Washington, v. 7, n. 12, p. 4337-4344, 1987.

DANGL, J. L.; RITTER, C.; GIBBON, M. J.; MUR, L. A. J.; WOOD, J. R.; GOSS, S.; MANSFIELD, J.; TAYLOR, J. D.; VIVIAN, A. Functional homologs of the Arabidopsis RPM1 disease resistance gene in bean and pea. Plant Cell, Rockville, v. 4, n. 11, p. 1359-1369, 1992.

DEAN, R. A.; KUC, J. Rapid lignification in response to wounding and infection as a mechanism for induced systemic protection in cucumber. Physiological and
Molecular Plant Pathology, London, v. 31, n. 1, p. 6981, 1987.

DELANEY, T. P.; UKNES, S.; VERNOOIJ, B.; FRIEDRICH, L.; WEYMANN, K.; NEGROTTO, D.; GAFFNEY, T.; GUTRELLA, M.; KESSMANN, H.; WARD, E.; RYALS, J. A central role of salicylic acid in plant disease resistance. Science, Washington, v. 266, n. 5188, p. 1247-1250, 1994.

DICKMAN, M. B.; PODILA, G. K.; KOLATUKUDY, P. E. Insertion of cutinase gene into a wound pathogen enables it to infect intact host. Nature, London, v. 342, n. 6248, p. 446-448, 1989.

DIGIORGIO, D.; CAMONI, L.; MOTT, K. A.; TAKEMOTO, J. Y.; BALLIO, A. Syringopeptins, Pseudomonas syringae pv syringae phytotoxins, resemble syringomycin in closing stomata. Plant Pathology, Oxford, v. 45, n. 3, p. 564-571, 1996.

DING, B. Cell-to-cell transport of macromolecules through plasmodesmata: a novel signalling pathway in plants. Trends in Cell Biology, Oxford, v. 7, n. 1, p. 5-9, 1997.

DOHERTY, D. G.; O'FARRELLY, C. Innate and adaptive lymphoid cells in the human liver. Immunological Reviews, Oxford, v. 174, p. 5-20, 2000.

DUSSOURD, D. E.; HOYLE, A. M. Poisoned plusiines: toxicity of milkweed latex and cardenolides to some generalist caterpillars. Chemoecology, Basel, v. 10, n. 1, p. 11-16, 2000.

ELLIS, J.; DODDS, P.; PRYOR, T. The generation of plant disease resistance gene specificities. Trends in Plant Science, London, v. 5, n. 9, p. 373-379, 2000.

ELLIS, J.; JONES, D. Structure and function of proteins controlling strain-specific pathogen resistance in plants. Current Opinion in Plant Biology, London, v. 1, n. 4, p. 288-293, 1998.

ENYEDI, A. J.; YALPANI, N.; SILVERMAN, P.; RASKIN, I. Localization, conjugation, and function of salicylic-acid in tobacco during the hypersensitive reaction to tobacco mosaic-virus. Proceedings of the National Academy of Sciences of the United States of America, Washington, v. 89, n. 6, p. 2480-2484, 1992.

FAVERY, B.; LECOMTE, P.; GIL, N.; BECHTOLD, N.; BOUCHEZ, D.; DALMASSO, A.; ABAD, P. RPE, a plant gene involved in early developmental steps of nematode feeding cells. EMBO Journal, Oxford, v. 17, n. 23, p. 6799-6811, 1998.

FLOR, H. H. Current status of the gene-for-gene concept. Annual Review of Phytopathology, Palo Alto, v. 9, p. 275296, 1971. 
GOETHALS, K.; VEREECKE, D.; JAZIRI, M.; MONTAGU, M. V.; HOLSTERS, M. Leafy Gall Formation by Rhodococcus fascians. Annual Review of Phytopathology, Palo Alto, v. 39, p. 27-52, 2001.

GREENBERG, J. T. Programmed cell death:a way of life for plants. Proceedings of the National Academy of Sciences of the United States of America, Washington, v. 93, n. 22, p. 12094-12097, 1996.

HALLAHAN, D. L. Monoterpenoid biosynthesis in glandular trichomes of Labiate plants. Advances in Botanical Research, San Diego, v. 31, p. 77-120, 2000.

HAMMERSCHMIDT, R. Phytoalexins:what have we learned after 60 years? Annual Review of Phytopathology, Palo Alto, v. 37, p. 285-306, 1999.

HARBORNE, J. B. Role of secondary metabolites in chemical defense-mechanisms in plants. ACS Symposium Series, Washington, v. 296, p. 22-35, 1986.

HEGNAUER, R. Biochemistry, distribution and taxonomic relevance of higher-plant alkaloids. Phytochemistry, Oxford, England, v. 27, n. 8, p. 24232427, 1988.

HULBERT, S. H.; WEBB, C. A.; SMITH, S. M.; SUN, Q. Resistance gene complexes: Evolution and utilization. Annual Review of Phytopathology, Palo Alto, v. 39, p. 285-312, 2001.

HUSSEY, R. S. Disease-inducing secretions of plantparasitic nematodes. Annual Review of Phytopathology, Palo Alto, v. 27, p. 123-141, 1989.

IRITI, M.; FAORO, F. Review of innate and specific immunity in plants and animals. Mycopathologia, Dordrecht, v. 164, n. 2, p. 57-64,2007.

JACOBI, W. R.; MAC DONALD, W. L. Colonization of resistant and susceptible oaks by Ceratocystis fagacearum. Phytopathology, St Paul, v. 70, n. 7, p. 618$623,1980$.

JENSEN, R. A. The shikimate arogenate pathway link between carbohydrate-metabolism and secondary metabolism. Physiologia Plantarum, Copenhagen, v. 66, n. 1, p. $164-168,1986$.

JONES, D. A. Why are so many food plants cyanogenic? Phytochemistry, Oxford, England, v. 47, n. 2, p. 155-162, 1998.

JONES, D. A.; JONES, J. D. G. The roles of leucine rich repeats in plant deference. Advances In Botanical Research. London, v. 24, p. 89-167, 1997.

KAJAVA, A. V. Structural diversity of leucine-rich repeat proteins. Journal of Molecular Biology, London, v. 277, n. 3, p. 519-527, 1998 .
KIRT, T. K. Effects of micro-organisms on lignin. Annual Review of Phytopathology, Palo Alto, v. 9, p. 185-210, 1971.

KITAJIMA, S.; SATO, F. Plant pathogenesis-related proteins: molecular mechanisms of gene expression and protein function. Journal of Biochemistry, Oxford, v. 125 , n. 1, p. 1-8, 1999.

KOLATUKUDY, P. E. Enzymatic penetration of the plant cuticle by fungal pathogens. Annual Review of Phytopathology, Palo Alto, v. 23, p. 223-250, 1985.

KOROLEVA, O. A.; DAVIES, A.; DEEKEN, R.; THORPE, M. R.; TOMOS, A. D.; HEDRICH, R. Indentification of a new glucosinolate-rich cell type in Arabidopsis flower stalk. Plant Physiology, Rockville, v. 124, n. 2, p. 599-608, 2000.

KOTHARI, I. L.; PATEL, M. Plant immunization. Indian Journal of Experimental Biology, Bangalore, v. 42, n. 3, p. 244-52, 2004.

KUHN, C.; FRANCESCHI, V. R.; SCHULZ, A.; LEMOINE, R.; FROMMER, W. B. Macromolecular trafficking indicated by localization and turnover of sucrose transporters in enucleate sieve elements. Science, Washington, v. 275, n. 5304, p. 1298-1300, 1997.

LAFITTE, C.; BARTHE, J. P.; MONTILLET, J. L.; TOUZE, A. Glycoprotein inhibitors of Colletotrichum lindemuthianum endopolygalacturonase in near isogenic lines of Phaseolus vulgaris resistant and susceptible to anthracnose. Physiological Plant Pathology, London, v. 25, n. 1, p. 39-53, 1984.

LAMBERT, K. N.; FERRIE, B. J.; NOMBELA, G.; BRENNER, E. D.; WILLIAMSON, V. M. Identification of genes whose transcripts accumulate rapidly in tomato after root-knot nematode infection Physiological and Molecular Plant Pathology, London, v. 55, n. 6, p. 341348, 1999.

LEDER, P.; HONJO, T.; PACKMAN, S.; SWAN, D.; NAU, M.; NORMAN, B. The organization and diversity of immunoglobulin genes. Proceedings of the National Academy of Sciences of the United States of America, Washington, v. 71, n. 12, p. 5109-5114, 1974.

LEULIER, F.; LEMAITRE, B. Toll-like receptors - taking an evolutionary approach. Nature Reviews Genetics, London, v. 9, n. 3, p165-178, 2008.

LINDSEY, K.; YEOMAN, M. M. The relationship between growth-rate, differentiation and alkaloid accumulation in cell-cultures. Journal of Experimental Botany, Oxford, v. 34, n. 145, p. 1055-1065, 1983.

LORENZO, G.; ITO, Y.; D'OVIDIO, R.; CERVONE, F.; ALBERSHEIM, P.; DARVILL, A. G. Host-pathogen 
interactions XXXVII. Abilities of the polygalacturonaseinhibiting proteins from four cultivars of Phaseolus vulgaris to inhibit the endopolygalacturonases from three races of Collectotrichum indemuthianum. Physiological and Molecular Plant Pathology, London, v. 36, n. 5, p. 421-435, 1990.

MA, R.; COHEN, M. B.; BERENBAUM, M. R.; SCHULER, M. A. Black swallowtail (Papilio polyxenes) alleles encode cytochrome P450s that selectively metabolize linear furanocoumarins. Archives of Biochemistry and Biophysics, San Diego, v. 310, n. 2, p. 332-340, 1994.

MALECK, K.; NEUENSCHWANDER, U.; CADE, R. M.; DIETRICH, R. A.; DANGL, J. L.; RYALS, J. A. Isolation and characterization of broad-spectrum diseaseresistant Arabidopsis mutants. Genetics, Chapel Hill, v. 160, n. 4, p. 1661-1671, 2002.

MARTY, F. Plant vacuoles. Plant Cell, Rockville, v. 11, n. 4, p. 587-599, 1999.

MAZAU, D.; ESQUERRÉ-TUGAYÉ, M. T. Hydroxyproline-rich glycoprotein accumulation in the cell walls of plants infected by various pathogens. Physiological and Molecular Plant Pathology, London, v. 29, n. 2, p. 147-157, 1986.

MCDONALD, K, L.; CAHILL, D. M. Evidence for a transmissible factor that causes rapid stomatal closure in soybean at sites adjacent to and remote from hypersensitive cell death induced by Phytophthora sojae. Physiological and Molecular Plant Pathology, London, v. 55, n. 3, p. 197-203, 1999.

MCDOWELL, J. M.; SIMON, S. A. Molecular diversity at the plant-pathogen interface. Developmental and Comparative Immunology, Oxford, v. 32, n. 7, p. 736744, 2008.

MENEZES, H.; JARED, C. Immunity in plants and animals: common ends through different means using similar tools. Comparative Biochemistry and Physiology C-Toxicology \& Pharmacology, New York, v. 132, n. 1, p. 1-7, 2002.

MEYER, S.; GENTY, B. Heterogeneous inhibition of photosynthesis over the leaf surface of Rosa rubiginosa L. during water stress and abscisic acid treatment: induction of a metabolic component by limitation of $\mathrm{CO} 2$ diffusion. Planta, Orsay, v. 210, n. 1, p. 126-131, 1999.

MEYERS, B. C.; DICKERMANN, A. W.; MICHELMORE, R. W.; SIVARAMAKRISHNAN, S.; SOBRAL, B. W.; YOUNG, N. D. Plant disease resistance genes encode members of an ancient and diverse protein family within the nucleotide binding super family. Plant Journal, Oxford, v. 20, n. 3, p. 317-332, 1999.
MOLLENHAUER, H. H.; HOPKINS, D. L. Xylem morphology of pierces disease-infected grapevines with different levels of tolerance. Physiological Plant Pathology, London, v. 9, n. 1, p. 95-100, 1976.

MORIMOTO, S.; SUEMORI, K.; MORIWAKI, J.; TAURA, F.; TANAKA, H.; ASO, M.; TANAKA, M.; SUEMUNE, H.; SHIMOHIGASHI, Y. Morphine metabolism in the opium poppy and its possible physiological function. Journal of Biological Chemistry, Bethesda, v. 276, n. 41, p. 38179-38184, 2001.

MORRISSEY, J. P.; WUBBEN, J. P.; OSBOURN, A. E. Stagonospora avenae secretes multiple enzymes that hydrolyze oat leaf saponins. Molecular Plant-Microbe Interactions, St Paul, United States, v. 13, n. 10, p. 1041$1052,2000$.

NIEBEL, A.; ALMEIDA-ENGLER, J.; HEMERLY, A.; FERREIRA, P.; INZE, D.; VAN MONTAGU, M.; GHEYSEN, G. Induction of $c d c 2 a$ and $c y c A t$ expression in Arabidopsis thaliana during early phases of nematodeinduced feeding cell formation. Plant Journal, Oxford, v. 10, n. 6, p. 1037-1043, 1996.

NYMAN, T.; JULKUNEN-TIITTO, R. Manipulation of the phenolic chemistry of willows by gall-inducing sawflies. Proceedings of the National Academy of Sciences of the United States of America, Washington, v. 97, n. 24, p. 13184-13187, 2000.

OSBOURN, A. Saponins and plant defence - a soap story. Trends in Plant Science, Oxford, v. 1, n. 1, p. 4-9, 1996.

PARK, S. W.; KAIMOYO, E.; KUMAR, D.; MOSHER, S.; KLESSIG, D. F. Methyl salicylate is a critical mobile signal for plant systemic acquired resistance. Science, Washington, v. 318, n. 5847, p113-116, 2007.

RAIRDAN, G; MOFFETT, P. Brothers in arms? Common and contrasting themes in pathogen perception by plant NB-LRR and animal NACHT-LRR proteins. Microbes and Infection, Amsterdam, v. 9, n. 5, p. 677-686, 2007.

RASK, L.; ANDRÉASSON, E.; EKBOM, B.; ERIKSSON, S.; PONTOPPIDAN, B.; MEIJER, J. Myrosinase: gene family evolution and herbivore defense in Brassicaceae. Plant Molecular Biology, Dordrecht, v. 42, n. 1, p. 93-113, 2000.

REID, J. L.; COLLMER, A. Construction and characterization of an Erwinia chrysanthemi mutant with directed deletions in all of the pectate-lyase structural genes. Molec. Plant-Microbe Interect. 1, 3238. Phytopathology, St Paul, v. 77, n. 12, p. 1719-1719, 1987. 
REPKE, K. R. H.; PORTIUS, H. J. Interaction of cardiac-glycosides and na,k-atpase is regulated by effector-controlled equilibrium between 2 limit enzyme conformers. Biochemical Pharmacology, Oxford, v. 33, n. 13, p. 2089-2099, 1984.

REYMOND, P.; WEBER, H.; DAMOND, M.; FARMER, E. E. Differential gene expression in response to mechanical wounding and insect feeding in Arabidopsis. Plant Cell, Rockville, v. 12, n. 5, p. 707-719, 2000.

RIDE, J. P. Lignification in wounded wheat leaves in response to fungi and its possible role in resistance. Physiological Plant Pathology, London, v. 5, n. 2, p. 125134, 1975.

ROBINSON, D.G. Clathrin-mediated trafficking. Trends in Plant Science, Oxford, v. 1, n. 10, p. 349-355, 1996.

SANG, Y.; BLECHA, F. Antimicrobial peptides and bacteriocins: alternatives to traditional antibiotics. Animal Health Research Reviews, Cambridge, v. 9, p. 227-235, 2008.

SARASTE, M.; SIBBALD, P. R.; WITTINGHOFER, A. The P-loop — a common motif in ATP- and GTP- binding proteins. Trends in Biochemical Sciences, Oxford, v. 15, n. 11, p. $430-435,1990$.

SCOTET, E.; NEDELLEC, S.; DEVILDER, M. C.; ALLAIN, S.; BONNEVILLE, M. Bridging innate and adaptive immunity through gamma delta T-dendritic cell crosstalk. Frontiers in Bioscience, Manhasset, v. 13, p. 6872-6885, 2008.

SHADLE, G. L.; WESLEY, S. V.; KORTH, K. L.; CHEN, F.; LAMB, C.; DIXON, R. A. Phenylpropanoid compounds and disease resistance in transgenic tobacco with altered expression of L-phenylalanine ammonialyase. Phytochemistry, Oxford, England, v. 64, n. 1, p. 153-161, 2003.

SEGURA, A.; MORENO, M.; MADUENO, F.; MOLINA, A.; GARCIA-OLMEDO, F. Snakin-1, a peptide from potato that is active against plant pathogens. Molecular Plant-Microbe Interactions, St Paul, v. 12, n. 1, p. 16-23, 1999.

SHULAEV, V.; SILVERMAN, P.; RASKIN, I. Airborne signalling by methyl salicylate in plant pathogen resistance. Nature, London, v. 385, n. 6618, p. 718-721, 1997.

SICKER, D.; FREY, M.; SCHULZ, M.; GIERL, A. Role of natural benzoxazinones in the survival strategy of plants. International Review of Cytology, San Diego, v. 198 , p. 319-346, 2000.

SIVASANKAR,S.; SHELDRICK, B.; ROTHSTEIN, S. J. Expression of allene oxide synthase determines defence gene activation in tomato. Plant Physiology, Rockville, v. 122, n. 4, p. 1335-1342, 2000.

STASKAWICZ, B. J.; MUDGETT, M, B.; DANGL, J. L.; GALAN, J. E. Common and contrasting themes of plant and animal diseases. Science, Washington, v. 292, n. 5525, p. 2285-2289, 2001.

STEGEMANN, C.; KOLOBOV, A. JR.; LEONOVA, Y. F.; KNAPPE, D.; SHAMOVA, O.; OVCHINNIKOVA, T. V.; KOKRYAKOV, V. N.; HOFFMANN, R. Isolation, purification and de novo sequencing of TBD-1, the first beta-defensin from leukocytes of reptiles. Proteomics, Weinheim, v. 9, n. 5, p. 1364-1373, 2009.

THIEL, G.; KREFT, M.; ZOREC, R. Unitary exocytotic and endocytotic events in Zea mays coleoptile protoplast. Plant Journal, Oxford, v. 13, n. 1, p. 117-120, 1998.

THOMPSON, J. N.; BURDON, J. J. Gene-for-gene coevolution between plants and parasites. Nature, London, v. 360, n. 6400, p. 121-125, 1992.

TOUZÉ, A.; ROSSIGNOL, M. Lignification and the onset of premunition in muskmelon plants. In: SOLHEIM, B.; RAA, J. Cell Wall Biochemistry Related to Specificity in Host-Plant Pathogen Interactions. Oslo: Univesitetsforlaget, 1977. p. 289-293.

VANETTEN, H.; TEMPORINI, E.; WASMANN, C. Phytoalexin (and phytoanticipin) tolerance as a virulence trait: why is it not required by all pathogens? Physiological and Molecular Plant Pathology, London, v. 59, n. 2, p. 83-93, 2001.

VLOT, A. C.; KLESSIG, D. F.; PARK, S. W. Systemic acquired resistance: the elusive signal(s). Current Opinion in Plant Biology, London, v. 11, n. 4, p. 436-442, 2008.

VOLOSHCHUK, N.; KNOP, M.; COLBY, T.; KOMBRINK, E.; HENNIG, L.; HOFMANN, D.; SICKER, D.; GRYGANSKI, A.; SCHULZ, M. How Doratomyces stemonitis copes with Benzoxazolin-2(3H)one (BOA), its derivatives and detoxification products Chemoecology, Basel, v. 17, n. 1, p. 1-12, 2007.

VON RAD, U.; HÜTTL, R.; LOTTSPEICH, F.; GIERL, A.; FREY, M. Two glucosyltransferases are involved in detoxification of benzoxazinoids in maize. Plant Journal, Oxford, v. 28, n. 6, p. 633-642, 2001.

WARD, E. R.; UKNES, S. J.; WILLIAMS, S. C.; DINCHER, S.S.; WIEDERHOLD, D. L.; ALEXANDER, D. C.; AHLGOY, P.; METRAUX, J. P.; RYALS. Coordinate gene activity in response to agents that induce systemic acquired-resistance. Plant Cell, Rockville, v. 3, n. 10 , p. $1085-1094,1991$. 
WHITTAKER, H.;FEENY,P.P.Allelochemics-chemical interactions between species. Science, Washington, v. 171, n. 3973, p. 757-770, 1971.

WITTSTOCK, U.; HALKIER, B. A. Cytochrome P450 CYP79A2 from Arabidopsis thaliana L. Catalyzes the conversion of L-phenylalanine to phenylacetaldoxime in the biosynthesis of benzylglucosinolate. The Journal of biological chemistry, Bethesda, v. 275, n. 19, p. 1465914666, 2000.
YOUNG, N. D. The genetic architecture of resistance. Current Opinion in Plant Biology, London, v. 3, n. 4, p. 285-290, 2000.

ZANGERL, A. R.; STANLEY, M. C.; BERENBAUM, M. R. Selection for chemical trait remixing in an invasive weed after reassociation with a coevolved specialist. Proceedings of the National Academy of Sciences of the United States of America, Washington, v. 105, n. 12, p. 4547-4552, 2008. 
